\title{
A TEORIA DO DESENVOLVIMENTO POLÍTICO E A QUESTÃO DA ORDEM E DA ESTABILIDADE
}

\author{
Natália Nóbrega de Mello
}

\begin{abstract}
RESUMO
O tema do artigo são teorias sobre o desenvolvimento político dos países pobres produzidas nos Estados Unidos que baseiam suas práticas científicas (a investigação, a classificação e a seleção de temas) em uma determinada representação do que definiria esses países. O artigo possui como questão de fundo a compreensão da passagem de uma representação desenvolvimentista e econômica para uma visão mais centrada na estabilidade e na ordem durante a década de 1960. Para tanto, debruça-se, primeiramente, sobre a série Studies in Political Development, do Committe on Comparative Politics. Com esse objeto é possível abarcar de forma privilegiada as transformações pela qual a teoria clássica teve que passar para abarcar o novo tema da instabilidade. Por fim, a análise das obras clássicas de Huntington indica quais são as características da nova representação que emerge. Dois aspectos-chave são investigados: (i) a representação dos países pobres e a relação que se estabelece entre a teoria do desenvolvimento político, a teoria do desenvolvimento econômico e a teoria da modernização; (ii) o significado de desenvolvimento político. A análise das obras indica que, por meio da inserção do tema da instabilidade, a teoria do desenvolvimento político se consolida como campo de estudos relevante e autônomo, uma vez que tal tema permitiu conceituar o seu objeto - desenvolvimento político - e argumentar que ele não poderia ser inteiramente reduzido à modernização social ou econômica.
\end{abstract}

PALAVRAS-CHAVE: representação; teoria do desenvolvimento; Estados Unidos; estabilidade; década de 1960.

\section{INTRODUÇÃO}

Em diversos países, o período posterior à II Guerra Mundial, época de freqüentes descolonizações, foi também o auge de diferentes teorias sobre o desenvolvimento e a modernização dos países. Antigas colônias, até então vistas como espaço de exotismo e aventura, passaram a ser percebidas por meio de uma nova perspectiva. No caso das teorias produzidas nos Estados Unidos, essa nova perspectiva entendia o problema desses países como resultado da fase de desenvolvimento em que ainda se encontravam. A solução era claramente a continuação e aceleração do processo de modernização que levasse esses países para uma etapa posterior na qual esses problemas estariam resolvidos. Naquele momento formou-se, portanto, um novo modo de descrição, de exposição, de caracterização ou, mais precisamente, de representação dos países pobres com base no qual foi possível entender os dilemas dos países pobres e tornar claro o caminho que deveria ser seguido para a transformação da atual condição.
Este artigo trata da representação dos países pobres que aparecem na teoria do "desenvolvimento político" norte-americana. Com o objetivo de recortar mais precisamente o objeto de pesquisa, iniciaremos o nosso percurso pela análise de duas citações que exemplificam a questão que nos interessa a respeito desse tema: "A maioria dos países é ainda preponderantemente rural; grande parte das populações compostas de analfabetos. A renda per capita nesses países permanece muito baixa. A mobilidade social e geográfica é relativamente alta no setor moderno, mas muito baixa no resto da sociedade. O elemento de subsistência persiste como fator importante na maioria das sociedades e a industrialização está apenas se iniciando ou é apenas uma aspiração. As estruturas centrais de governo são, em muitos casos, modernas na sua forma, mas as funções políticas e autoritárias tendem a ser exercidas por meio de uma variedade de estruturas mistas englobando elementos modernos e tradicionais. Estas misturas de modernidade e tradicionalismo são, em 
alguns casos, de caráter fusionista e, em outros, isolacionista" (ALMOND \& COLEMAN, 1969, p. 502; grifos no original).

"A emergência e a queda de estados-nação não é uma novidade, mas na era moderna, quando os Estados constituem os blocos fundadores de uma ordem internacional legítima, a desintegração violenta e a palpável fraqueza de alguns Estados na África, Ásia, Oceania e América Latina ameaça a própria fundação deste sistema. Organizações internacionais e grandes potências, conseqüentemente, se encontram engolidas, de forma perturbadora, por um redemoinho de conflito interno anômico e ajuda humanitária desordenada. Normas internacionais desejáveis como a estabilidade e a previsibilidade se tornam difíceis de serem alcançadas quando tantos novos estados-nação no globo oscilam precariamente entre a fraqueza e o fracasso, com alguns realmente fracassando, ou até mesmo colapsando. Em uma era de terror, apreciar a natureza do fracasso estatal e responder as suas dinâmicas se tornaram questões ainda mais centrais para os debates políticos mais importantes" (ROTBERG, 2003, p. 1)

A mudança representacional entre a primeira perspectiva teórica e a segunda sobressai-se, mesmo para um leitor desatento. Na primeira citação, os países pobres ${ }^{1}$ são representados acima de tudo a partir da chave econômica e nacional, isto é, como países que sofrem de problemas explicáveis pelo seu grau nacional de desenvolvimento ou modernização ${ }^{2}$. A segunda citação revela algumas discussões, predominantes na Ciência Política dos Estados Unidos da década de 1980 até hoje, nas quais os países pobres são representados como um grupo de países que são fonte de conflitos, imigração, ameaças diversas, terrorismo etc., ou seja, a chave de interpretação é a segurança e a esfera internacional.

1 A utilização dos termos "países ricos"e "países pobres" para tratar o relacionamento entre esses dois grupos de países toma esses termos como categorias descritivas, sem atribuir, portanto, qualquer conteúdo analítico a eles.

2 Não por acaso, desenvolvimento e modernização aparecem aqui sem nenhum adjetivo complementar. Nessa épo$\mathrm{ca}$, apesar do interesse em entender o sistema político dos países que estão sofrendo profundas transformações, ainda não há nenhuma proposição conceitual, teórica ou mesmo programática de formular uma teoria do desenvolvimento político como separada da modernização como um todo, ou meramente separada do desenvolvimento econômico. Esse ponto ficará mais claro abaixo.
Tendo como questão de fundo essa mudança representacional, o presente artigo debruça-se sobre o período de transformação do pensamento desenvolvimentista clássico - década de 1960 quando foi produzida uma chave de idéias ainda comprometidas com um passado desenvolvimentista, mas que já apontam para um futuro securitizado. Não será tratado aqui, portanto, como chegamos a esse destino final securitizado exemplificado pela citação de Rotberg, mas apenas o caminho trilhado no início desta trajetória. Além de já apresentar deslocamentos em direção a uma nova representação, essa década é crucial para a compreensão das transformações por qual a teoria clássica teve que passar para abarcar esse novo tema.

Como o objetivo é entender as transformações que ocorreram para que uma nova abordagem fosse gerada, foi eleito como objeto de pesquisa inicial a série de publicações do Committee on Comparative Politics (CCP) ${ }^{3}$, "Estudos do Desenvolvimento Político". Essa série é um caso de estudos privilegiado para o objetivo de pesquisa porque, em primeiro lugar, ainda segue, em seus volumes iniciais, a teoria clássica do desenvolvimento, afastando-se da perspectiva clássica nos últimos anos ${ }^{4}$. Dessa forma, essa série permite o

3 O Comitê de Política Comparada pertence ao Conselho de Pesquisa em Ciências Sociais (Social Science Research Council, SSRC), formado na década de 1920 com financiamento da Fundação Rockefeller (posteriormente recebe auxílio também das fundações Ford e Carnegie). O Conselho tem como principal objetivo a reunião de pesquisadores de diferentes universidades, organizados em torno de comitês de áreas ou problemas de pesquisa. O Comitê destacou-se por ter sido o primeiro grupo de comparativistas políticos norte-americanos a considerar os países não ocidentais como objetos válidos de pesquisa empírica sistemática. $\mathrm{Ou}$ seja, esses autores partiram de um campo tradicional na Ciência Política - o de política comparada - mas deslocaram o objeto de estudo desse campo. Se a área de política comparada até então estava inteiramente voltada para entender (mais do que comparar) as instituições políticas nas grandes potências, a nova proposta é pesquisar a política no mundo pós-colonial e compará-la com a dos países desenvolvidos. A esse grupo pertence a obra clássica de Almond e Coleman, A politica das áreas em desenvolvimento (cf. ALMOND \& COLEMAN, 1969).

4 Diferente de Huntington, que alcançou uma notoriedade única com o artigo crítico da perspectiva clássica, "Political Development and Political Decay” (HUNTINGTON, 1965), mas que não possui artigos e livros anteriores comprometidos com essa abordagem que permitissem uma análise das transformações que ocorreram em seu pensamento. 
acompanhamento da evolução teórica de um grupo de estudos, em contraste com a apresentação de clássicos pertencentes a diversos grupos ou diversas formas de abordagens, o que garante maior clareza: $(i)$ à análise de como, dentro de um mesmo paradigma e entre um mesmo grupo de pesquisadores, apareceram novos temas; (ii) às conseqüências que trouxeram para o paradigma como um todo.

Em segundo lugar, mesmo que a série do Comitê de Política Comparada como um todo, diferentemente de Huntington, não esteja presente até hoje na lista de obras obrigatórias da teoria do desenvolvimento político dos EUA, ainda assim não é possível renegar a importância que esse Comitê e sua série "Estudos do Desenvolvimento Político" possuíam em sua época. Essas obras não só tiveram amplo espaço em seu período sendo inclusive um dos objetos privilegiados de discussão no artigo clássico de Huntington e no livro posterior que dá prosseguimento à reflexão do artigo -, como não se pode negar o quanto o CCP pautava as discussões de sua época. As citações abaixo confirmam esse ponto: "Atenção particular é devotada para os dez membros líderes do "Comitê de Política Comparada" do "Conselho de Pesquisa em Ciência Social", grupo que foi muito importante em assegurar um alto grau de coesão teórica no estudo da modernização política"5 (O'BRIEN, 1972, p. 352). "Devido ao papel central [do CCP] na articulação de uma agenda para o campo, sua influência sobre a distribuição de recursos, e seu alto nível de prestígio profissional, este comitê fornece um caso particularmente bom para a análise" (LATHAM, 2000 , p. 37). "Poucos grupos acadêmicos formalizados determinaram tão perfeitamente o curso de um segmento da ciência social como o fez o comitê durante esta década" (PACKENHAM, 1973, p. 224).

Após a discussão a respeito das transformações ocorridas no pensamento clássico para a emergência de uma nova base representacional dos países pobres, este artigo debruça-se ainda sobre as obras da década de 1960 do cientista político Samuel Huntington. Essas obras afirmaram, antes de quaisquer outras e com uma ênfase até hoje

\footnotetext{
5 As citações de publicações em língua estrangeira foram traduzidas pela autora (nota do revisor).
}

única, que: $(i)$ o desenvolvimento político não era inevitável (não era, portanto, um destino certo) e tanto a decadência política quanto o desenvolvimento eram um resultado possível; (ii) a modernização social era produtora de instabilidade e decadência. Essa perspectiva caminhava, portanto, em sentido contrário à teoria clássica que a colocava como motor inevitável do desenvolvimento político. Por esses motivos, Huntington emerge como um objeto de estudo único para a análise das novas bases da representação que se forma, na qual o ponto de vista clássico do desenvolvimento já foi completamente abandonado ${ }^{6}$.

O modo como essa representação desenvolvimentista evoluiu na série do Comitê de Política Comparada (CCP) e a transformação teórica alcançada nas obras de Huntington são tratados a partir de dois aspectos-chaves: $(i)$ o relacionamento entre a teoria do desenvolvimento político, a teoria do desenvolvimento econômico e a teoria da modernização no nível representacional e (ii) o modo como se entende o desenvolvimento político.

Em suma, o objetivo deste artigo é entender a mudança na representação dos países pobres na teoria do desenvolvimento político dos Estados Unidos a partir da análise de obras do Comitê de Política Comparada e do cientista político Samuel Huntington produzidas durante a década de 1960.

É necessário ressaltar que esse recorte teórico não deve ser entendido como uma negligência em relação ao contexto em que essas mudanças internas ocorreram e em relação ao modo como o ambiente externo afetou o desenvolvimento teórico. De fato, tais transformações políticas não são o foco deste artigo, tampouco o efeito destas na teorização acadêmica ${ }^{7}$. Nosso objetivo, ao considerar as obras sobre a teoria do desenvolvimento político internamente, é discutir em que medida aquelas mudanças contribuíram para um novo entendimento dos países pobres e de seus proble-

\footnotetext{
6 Um survey realizado por Kenski torna completa a argüição da importância de Huntington. Segundo esse survey, de 1974, os cientistas apontaram majoritariamente o livro do autor como obra mais importante sobre o desenvolvimento político $(57,6 \%)$ e mais útil $(59,4 \%)$ (KENKSI, 1975).

7 Uma análise a respeito do modo que os acontecimentos externos influenciaram a transformação interna teórica pode ser encontrada em Mello (2009).
} 
mas e, consequentemente, para a elaboração de uma nova concepção a respeito da ação política necessária.

Antes de iniciarmos a investigação propriamente dita, a próxima seção introduz brevemente os títulos que serviram de base para destrinchar as principais características dessa bibliografia.

\section{AS OBRAS}

As características mais importantes do pensamento clássico da teoria do desenvolvimento que são brevemente retomadas neste artigo, com o intuito de comparação, tiveram por base cinco obras, consideradas as mais importantes no assunto. Essas obras são: The Structure of Society, de Marion Levy Jr. (1952); The Passing of Traditional Society: Modernizing the Middle East, de Daniel Lerner (1958); A política das áreas em desenvolvimento, editado por Gabriel Almond e James Coleman (1969); e os artigos de Edward Shils (1960a; 1960b), "Political Development in the New States" I e II e de Karl Deutsch (1961), "Social Mobilization and Political Development". Sobre os conceitos e inovações principais de cada uma dessas obras, ver Gendzier (1985) e Gilman (2003).

Para analisar a evolução da teoria clássica, foram tratadas as obras da série "Estudos sobre Desenvolvimento Político" (Studies in Political Development), do Comitê de Política Comparada (CCP).

A série "Estudos do desenvolvimento político" foi publicada entre 1963-1966, em seis volumes $^{8}$. Todos eles, com exceção do terceiro, estão dedicados a entender a correlação entre uma determinada variável e o desenvolvimento político. Esse propósito está exposto desde os títulos: "Comunicações e desenvolvimento político", "Burocracia e desenvolvimento político", "Educação e

\footnotetext{
8 Após um intervalo de cinco anos sem nenhuma publicação, em 1971 é editado o volume Crises and Sequences in Political Development, por Binder et alii (1971), seguido por The Formation of National States in Western Europe, de Charles Tilly (1975) e Crises of Political Development in Europe and the United States, de Raymond Grew (1978).

Esses últimos volumes resultam do objetivo de se consolidar uma linha de pesquisa que emerge durante a discussão da década de 1960. Como nosso objetivo é acompanhar a mudança representacional na teoria do desenvolvimento político na década de 1960, os volumes da década de 1970 não estão incluídos na análise.
}

desenvolvimento político", "Cultura política e desenvolvimento político" e, por último, "Partidos políticos e desenvolvimento político". Apesar do terceiro volume apresentar um título diferenciado ("Modernização política no Japão e na Turquia"), seu objetivo também é compreender e medir a relação de variáveis sócio-políticas (só que neste caso no plural) e o desenvolvimento político; compreensão essa que permitiria no futuro construir uma teoria geral do desenvolvimento político9.

A base metodológica ainda é o funcionalismo que já aparecia na obra fundamental de Almond e Coleman (1969), ainda que isso não signifique que todos os capítulos ${ }^{10}$ sejam funcionalmente orientados. Segundo Montgomery (1969), dos 98 capítulos que compõem a série, mais de um terço (36) é funcionalmente ou "operacionalmente" orientado; estudos institucionais são quase tão numerosos quanto e 28 são investigações históricas. Apesar do propósito comparativo, quarenta e oito (ou quase a metade) dos capítulos são monografias a respeito de um só país. A distribuição geográfica dos países tratados é: trinta e quatro são da Ásia e do Oriente Próximo, catorze são sobre a Europa e a América do Norte, doze dedicam-se a África e apenas três dissertam sobre a América Latina. O nível nacional domina as pesquisas da série, sendo que 27 voltam-se para o nível individual. Um dos pontos que mais nos interessam nessa classificação, e que será mais bem compreendido a seguir, é que quase todos os ensaios fazem uso muito mais extenso da Sociologia, Antropologia e Psicologia Social do que da Economia. Passemos, então, às obras de Huntington.

No artigo "Political Development and Political Decay", de 1965, Samuel Huntington anuncia o objetivo de distinguir "desenvolvimento político" de "modernização". Segundo ele, desenvolvimento político seria o processo de institucionalização de organizações políticas e procedimentos, en-

9 Os volumes utilizados para análise de cada uma das obras são os seguintes: Coleman (1965), Pye (1967), Ward e Rustow (1968), Pye e Verba (1969), La Palombara e Weiner (1972) e La Palombara (1973).

10 Os livros foram editados por membros do Comitê com a participação de diversos autores na produção dos numerosos capítulos. Com exceção do volume de Pye e Verba (1969), todos os volumes são produto de uma conferência sobre o tema. 
quanto modernização estaria relacionada, acima de tudo, à mobilização e à participação política. $\mathrm{O}$ primeiro parágrafo já anuncia sua tese principal: "Crescimentos rápidos na mobilização e participação, os aspectos políticos principais da modernização, minam as instituições políticas. Uma modernização rápida, em síntese, não produz desenvolvimento político, mas decadência política" (HUNTINGTON, 1965, p. 386). Outra novidade de Huntington foi anunciar, na contramão dos estudos feitos, que, para entender as sociedades em mudança, uma teoria da decadência política seria muito mais útil que uma teoria do desenvolvimento. $\mathrm{O}$ artigo finaliza ainda realizando um breve esboço de estratégias para o desenvolvimento institucional.

Em $A$ ordem política nas sociedades em mudança, Huntington (1975; originalmente de 1968) continua entendendo a modernização como essencialmente desestabilizadora; o desenvolvimento institucional como promovedor da ordem política e a decadência política como uma situação em que há uma rápida mudança social e mobilização acompanhada de um desenvolvimento lento das instituições. De original, uma classificação de diferentes sociedades a partir de dois critérios: participação e institucionalização ${ }^{11}$. A história da construção da ordem política nos Estados Unidos e na Europa é retomada e discute-se a possibilidade de construção da ordem política: (1) a partir de uma comunidade política tradicional; (2) a partir de uma sociedade pretoriana, (3) por meio da revolução, (4) por meio da reforma e (5) por meio de partidos políticos.

III. O DESENVOLVIMENTO POLÍTICO NA SÉRIE "ESTUDOS DO DESENVOLVIMENTO POLÍTICO” E A DISCUSSÃO COM A REPRESENTAÇÃO ECONÔMICA DOS PAIISES POBRES

A principal característica da nova representação dos países pobres que irá emergir com a teoria do desenvolvimento é a intenção de abranger

11 As sociedades modernas são aquelas com alta participação, subdivididas entre desenvolvidas (além de alta participação, alta institucionalização) e subdesenvolvidas (em que a institucionalização é baixa). Uma segunda clivagem refere-se apenas ao grau de institucionalização política (deixando de lado, portanto, a participação). As altamente institucionalizadas são sociedades cívicas, enquanto as de baixo grau são pretorianas. as transformações em curso nesses países, considerando-os, portanto, em seu aspecto dinâmico. Essa novidade é difícil de captar hoje, entretanto, até finais da década de 1940, os países tradicionais eram estudados nos Estados Unidos (e também na Europa) basicamente em duas áreas: a Antropologia e os estudos orientalistas. Na Antropologia, o foco de pesquisas preferencial eram as populações que ainda não haviam sofrido contato com a civilização ocidental. Já os orientalistas tinham como principal interesse a investigação de civilizações orientais, mas civilizações que estavam historicamente congeladas, ou seja, que apesar de possuírem um passado extremamente rico, haviam perdido o "bonde do progresso" e ficaram "paradas no tempo". Dedicavam-se principalmente ao estudo dos textos clássicos orientais e somente então os resultados desses estudos eram transportados para a aplicação ao Oriente contemporâneo. Ou seja, esse modo de abarcar realidades não Ocidentais permitia a transferência direta e sem necessidade de complementos de características esmiuçadas em textos clássicos para a realidade contemporânea dos países. Dessa forma, quando as sociedades tradicionais eram objeto de investigação, tanto na Antropologia quanto nos estudos orientalistas norte-americanos, $\mathrm{o}$ foco incidia sobre a não-historicidade desses povos e civilizações (WALLERSTEIN, 1998).

O ponto mais fundamental a ser esclarecido sobre a nova representação dinâmica presente nas obras clássicas do desenvolvimento é que a fonte para uma visão que assume a historicidade desses países será, prioritariamente, a teoria do desenvolvimento econômico. Isto é, a base que permitiu uma nova visão não-estática dos países pobres foi o referencial econômico e as variáveis analíticas que o acompanham. Um bom exemplo desse embasamento aparece na citação inicial deste artigo retirada do capítulo final do artigo de Almond e Coleman (1969), escrito por Coleman com o objetivo de fazer um balanço geral da situação dos países em desenvolvimento como um todo ${ }^{12}$.

Com o desenrolar da teoria clássica, inaugurase ao longo da série do CCP um novo tipo de relacionamento entre a teoria do desenvolvimento

12 O livro inicia com um capítulo de Almond, em que se apresenta a proposição teórico-analítica que depois é aplicada à situação dos países em cada região (Ásia, África e América Latina). Coleman finaliza com um balanço geral dos países em desenvolvimento. 
econômico e a teoria do desenvolvimento político. Esse novo relacionamento será marcado por um progressivo afastamento da representação econômica, entretanto, a teoria do desenvolvimento econômico não deixará de ser uma perspectiva-chave com a qual se dialoga.

O primeiro passo em direção a esse afastamento é percebido na crítica ao papel hegemônico ocupado pela teoria do desenvolvimento econômico em diversos âmbitos. No nível político, a negligência do desenvolvimento político nas ajudas externas aos países pobres é denunciada. No nível conceitual, defende-se a necessidade de romper-se com a submissão do entendimento do sistema político moderno às categorias de modernidade social e econômica. Finalmente, no nível representacional percebe-se uma formulação cada vez mais autossuficiente, com variáveis e medidas políticas, para representar-se o país em desenvolvimento. No volume editado por Coleman - o quarto da série - a representação ambivalente, pautada em termos econômicos e políticos, parece ter sido finalmente superada, e a teoria do desenvolvimento político demonstra ter alcançado um status capaz de prescindir, ao menos na descrição do seu próprio objeto, do apoio em variáveis econômicas. É o que aparece na citação a seguir: “À primeira vista pareceria que a Indonésia nunca teve os elementos básicos para um Estado viável. Ela é geograficamente fragmentada -3000 ou mais ilhas dispersas por um arco de $3000 \mathrm{mi}-$ lhas. Seus grandes recursos e imensa população estão desigualmente distribuídos $-75 \%$ das pessoas residem em Java e $75 \%$ da riqueza econômica se encontra nas ilhas fora de Java. Religiões e seitas são abundantes na Indonésia - variedades do Islã, Hinduísmo, Catolicismo, Protestantismo $\mathrm{e}$ as crenças indígenas que abarcamos genericamente como animismo. O país foi dominado por príncipes indianos, capitães marinhos portugueses, um lord inglês, mercantilistas holandeses e militares japoneses. Com essas condições a Indonésia conseguiu, ainda assim, persistir como um Estado desde a Independência apesar de duas ocupações militares européias e grandes insurreições em Sumatra e Célebes. Com certeza, muitos desses fatos contribuíram para a desunião, mas existem elementos harmônicos também" (COLEMAN, 1965, p. 115; grifo no original).

A citação demonstra de modo exemplar como mesmo buscando uma descrição detalhada e extensa do sistema político e das possibilidades de integração nele, ainda assim não aparece nenhuma necessidade do autor em recorrer aos termos econômicos.

Mas o que permite essa mudança? O primeiro ponto que chama a atenção é que o volume anterior (WARD \& RUSTOW, 1968) insere, de modo inaugural, uma questão até então ausente no debate do CCP, a qual será o fio condutor que acompanhará os próximos volumes da série até a sua extinção ${ }^{13}$. Esse novo tema é a questão das crises e problemas enfrentados pelos países durante a sua trajetória de desenvolvimento. No livro de Ward e Rustow (1968), procura-se investigar se é possível delinear padrões de desenvolvimento tendo em vista o modo que as crises são enfrentadas em cada país e a seqüência em que elas aparecem.

Não é a mera novidade da questão que nos interessa, mas o papel que essa ocupa na análise, ou ainda, a justificativa que é dada para que um novo tema seja introduzido entre aqueles que já eram clássicos na literatura. Retomando, o estudo do modo que as crises nos países foram enfrentadas e a seqüência em que elas aconteceram seria um modo de descobrirem-se padrões de desenvolvimento; investigação essencial para construir uma teoria comparada do desenvolvimento, isto é, da dinâmica de mudança. Os autores criticam que, até então, a área de política comparada só havia conseguido realizar comparações entre os países a partir de uma perspectiva estática, porque compara diversos países em certo período do tempo. Comparariam nações assim como comparariam retratos ${ }^{14}$. O enfoque das crises e seqüências seria a base para a construção de uma nova linha de pesquisa que conseguisse abarcar o desenvolvimento diacronicamente.

É justamente esse papel das crises e seqüências na construção de uma análise dinâmica ou diacrônica, que aponta para uma nova situação em que a teoria do desenvolvimento político prescinde da teoria do desenvolvimento econômico para

13 Essa questão emergente vai ocupar cada vez mais um espaço central nos volumes da série, até a sua finalização com um livro totalmente voltado para discutir as crises e seqüências no desenvolvimento político (BINDER et alii, 1971).

14 Ward e Rustow afirmam que o próprio livro fundamental do CCP de Almond e Coleman (1969) seria um ótimo exemplo dessa comparação estática. 
ter uma imagem dinâmica dos países em transição. Na teoria clássica, uma representação dinâmica significava uma visão que atentasse para as transformações que ocorriam contemporaneamente naqueles países, uma visão que não igualava passado, presente e futuro como se fossem um mesmo estado nos países não-Ocidentais; em outras palavras, uma visão que percebesse a chegada de elementos dinâmicos nesses países. $\mathrm{O}$ significado reivindicado por Ward e Rustow (idem) para o termo dinamismo não é mais apenas a percepção das transformações em curso nesses países, mas entender o processo diacrônico de desenvolvimento. Mesmo com essas diferenciações de significado para o termo dinâmico, e considerando ainda a diferença de período entre a nova proposição de Ward e Rustow e os conflitos e disputas que existiam no período dos clássicos, ainda assim é possível relacionar, de um lado, a emergência de um novo elemento capaz de fornecer dinamismo à análise, elemento esse autóctone ao arsenal da teoria do desenvolvimento político, e de outro lado, o processo de autonomização dessa teoria.

Outra novidade que emerge com a evolução da teoria clássica é a questão do desenvolvimento político. O interesse pelo sistema político, é claro, já existia desde os clássicos, mas ele era estudado em sua relação com a modernização social ou desenvolvimento econômico, não havendo uma discussão sobre o que seria o desenvolvimento político em si.

A submissão da conceituação do desenvolvimento político ao processo total de modernização começa a ser, nesta geração, rejeitada. Propõe-se então como objetivo definir o que seria o desenvolvimento político, entendido então como processo específico e relativamente independente do desenvolvimento econômico e social. A definição de desenvolvimento político será dada por Coleman, conforme aparece na citação a seguir: "Nesses termos, o desenvolvimento político pode ser entendido como a aquisição por um sistema político de uma capacidade política, conscientemente perseguida e qualitativamente nova e elevada, como é manifestada pela institucionalização exitosa de (1) novos padrões de integração que regulam e que contêm as tensões e os conflitos produzidos pela crescente diferenciação; (2) novos padrões de participação e distribuição de recursos adequadamente responsivos às demandas geradas pelos imperativos de igualdade" (COLEMAN, 1965, p. 15; grifos no original).

É impossível não enxergar nessa definição de desenvolvimento político - processo de aquisição de capacidade para integração, no sentido de regulação e contenção de conflitos e capacidade para distribuição no sentido de resposta às demandas - uma solução aos anseios que acompanham os escritos dessa série. Aqui se consegue chegar a uma definição de desenvolvimento político como processo específico e diferente do processo econômico, ainda que sofra de alguma forma efeitos dos avanços na esfera da economia.

Além disso, tal definição responde a uma preocupação que vai ganhando cada vez mais espaço nos volumes da série: a apreensão em relação ao curso dos países em desenvolvimento. O processo de aquisição de capacidade ou desenvolvimento político aparece, então, intimamente ligado à reação a conflitos ou tensões e demandas. Ou seja, o novo tema de crises e seqüências é inserido no próprio conceito de desenvolvimento. "Desenvolver-se" é ser capaz de apagar os conflitos e satisfazer ou controlar as demandas emergentes. "Desenvolvidos" são aqueles que realizam de maneira satisfatória essas duas funções. "Em desenvolvimento" são os sistemas políticos que ainda não adquiriram capacidade suficiente para a realização dessas funções. Portanto, o sistema político de uma sociedade, ao contrário de reflexo de sua modernidade ou industrialização, é aquele que emerge em função da forma e da seqüência em que os problemas e crises foram tratados naquele país.

Esse novo modo de entender o desenvolvimento político como um processo relativamente autônomo e os novos temas introduzidos chegam a inverter algumas questões do debate dos clássicos. Inverter, pois, se os clássicos viam-se fortemente constrangidos a dialogar nos termos da teoria do desenvolvimento econômico para alcançarem reconhecimento de suas pesquisas, isto é, a apontarem e justificarem no próprio estudo a utilidade de tratar dos fatores não econômicos do desenvolvimento. Aqui, o desenvolvimento político, como processo separado, parece estar a tal ponto consolidado que os dois últimos livros da série chegam a perguntar-se sobre a utilidade do crescimento econômico para o desenvolvimento político. Mesmo a modernização e a racionaliza- 
ção são medidas pelo valor que possuem para o estabelecimento do sistema político. Sendo que "desenvolvimento político" vai adquirindo cada vez mais o significado de estabilidade.

Vimos até agora, portanto, como a série do CCP produziu, na década de 1960 , o objeto de desenvolvimento político como autônomo ao processo econômico e também um tema autóctone para representar o país em desenvolvimento a partir de uma perspectiva dinâmica. Se considerarmos que uma disciplina constitui-se enquanto tal quando consegue argumentar, com sucesso, que seu objeto de estudo não pode ser inteiramente explicado por outras disciplinas, isto é, que o desenvolvimento político não pode ser reduzido à modernização social e econômica, o que vemos evoluir na série do CCP é a consolidação de uma teoria do desenvolvimento político como campo de estudos relevante e autônomo na área do desenvolvimento. O que nos interessa aqui, no que diz respeito à nossa questão de fundo, é que esse processo de consolidação da teoria do desenvolvimento político como campo teórico autônomo é inseparável da inserção do tema da instabilidade.

\section{A OPOSIÇÃO ENTRE MODERNIZAÇÃO E INSTITUCIONALIZAÇÃO EM SAMUEL HUNTINGTON}

A crítica tão constante entre os cientistas do $\mathrm{CCP}$ à predominância da teoria do desenvolvimento econômico torna-se menos relevante nos textos de Huntington ${ }^{15}$. $\mathrm{O}$ argumento defendido neste artigo é que a baixa repercussão dessa crítica em Huntington ocorre porque, enquanto para os cientistas do CCP a teoria do desenvolvimento econômico forma a base-chave da qual a teoria do desenvolvimento político busca desvencilhar-se, para Huntington o processo de autonomização teórica assume objetivos mais ambiciosos, por buscar distinguir-se da teoria da modernização como um todo.

O problema a que Huntington opõe-se com mais veemência é a deficiente precisão do conceito de desenvolvimento político, que apenas se confunde com o de modernização. Segundo Huntington $(1965 ; 1975)$, apesar de existir uma multiplicidade de definições para o desenvolvimen-

15 Essa crítica aparece apenas uma vez no livro (HUNTINGTON, 1975, p. 17) e no artigo (HUNTINGTON, 1965, p. 428-429). to político, é possível identificar duas características que aparecem em diferentes abordagens. Primeiro, ele é geralmente identificado, ou está intimamente conectado, com um aspecto da modernização da sociedade como um todo. Conseqüentemente, em segundo lugar, é necessário o uso de uma série de critérios para medir o desenvolvimento político, já que a modernização é um processo amplo e complexo ${ }^{16}$.

Em primeiro lugar, sua rejeição da confusão entre modernização e desenvolvimento político está fundamentada em uma análise da perda de precisão conceitual que essa associação implica. Ao conectar desenvolvimento político e modernização, a análise fica restrita aos países que estão modernizando-se, portanto, tal análise torna-se incapaz de perceber em que medida antigas civilizações e impérios possuíam ou não um sistema político desenvolvido. Uma das vantagens de diferenciarem-se os conceitos seria, dessa forma, liberar o conceito de desenvolvimento político de uma identificação com o processo ocidental e, ainda, conseguir-se-ia alcançar clareza a respeito do que é atualmente específico no processo em curso na Ásia, na África e na América Latina (HUNTINGTON, 1965).

Em segundo lugar, é o critério de fidedignidade que justifica uma separação clara entre modernização e desenvolvimento político (idem) ${ }^{17}$. Huntington afirma que se a modernização, em certos sentidos, é um fato nessas regiões do mundo, o caso do desenvolvimento político é totalmente diverso. Segundo ele, este último processo não reflete nem de longe a realidade desses países, marcada por violências, golpes, corrupção etc. O uso de variáveis da modernização para medir o suposto desenvolvimento político desses países

\footnotetext{
16 Os critérios que geralmente aparecem, no artigo (idem), são a racionalização, a integração, a democratização e a participação. No livro, de 1968, o autor ressalta a racionalização, a diferenciação e a participação (HUNTINGTON, 1975).

17 Essa justificativa em duas etapas para a distinção entre modernização e desenvolvimento político aparece no artigo de 1965 . Nele, a primeira justificativa para a melhor distinção entre os conceitos - aquela que aponta a vantagem propriamente conceitual - sustenta-se na discussão feita com diversos autores sobre o significado de desenvolvimento político. Diversamente, no livro, a discussão com a bibliografia a respeito do significado de desenvolvimento político ocupa um espaço bem menor e, conseqüentemente, somente a segunda justificativa está presente.
} 
gera uma falsa sensação de que eles estão progredindo e até mesmo que o processo é inevitável ${ }^{18}$, quando, na realidade, as sociedades em mudança encontram-se em meio a um processo de decadência política. Nesse sentido, Huntington afirma que, para entender o processo pelo qual estão passando esses países é necessário, acima de tudo, teorias sobre a decadência ou desintegração política, e não sobre o desenvolvimento político (HUNTINGTON, 1965; 1975).

Esclarecidas as justificativas para a distinção entre modernização e desenvolvimento político, já se pode focar suas bases.

Huntington ressalta dois aspectos da modernização como os mais relevantes para a política: a mobilização social e o desenvolvimento econômico (idem). Mobilização social, conforme Deutsch (1961), é o fenômeno por meio do qual antigos comprometimentos são destruídos e novos padrões de comportamento e socialização emergem. Segundo Huntington, a mobilização social afeta diretamente a política porque altera as aspirações de indivíduos, grupos ou sociedades; enquanto o

18 A citação a seguir explica como uma definição de desenvolvimento político que inclua elementos da modernização permite ver o desenvolvimento político como um processo inevitável: "Além do mais, quanto mais ampla a definição de desenvolvimento, mais inevitável se torna o desenvolvimento. As definições completamente abrangentes fazem com que o desenvolvimento pareça fácil por fazê-lo parecer inevitável. O desenvolvimento se torna uma causa primeira onipresente, que explica tudo, mas não distingue nada. Quase tudo que acontece nos países 'em desenvolvimento' - golpes, lutas étnicas, guerras revolucionárias - se torna parte do processo de desenvolvimento, ainda que isso pareça contraditório ou regressivo na superfície. O desenvolvimento político perde seu conteúdo analítico e adquire um conteúdo meramente geográfico. No extremo, se torna sinônimo da história política da Ásia, África e América Latina" (HUNTINGTON, 1965, p. 390). Apesar de o artigo ter sido publicado quando o tema das crises estava apenas entrando na agenda do CCP, não é possível ignorar a discussão entre Huntington e a série "Estudos do Desenvolvimento Político". Enquanto os autores da série estão inserindo as crises no próprio desenvolvimento político (sendo que esse não é totalmente diferente de modernização exceto na versão de Coleman (1965)), Huntington denuncia o absurdo de correlacionar-se desenvolvimento com golpes e guerras, obscurecendo o que estes realmente são: sintomas da decadência política. Indicam que essa era uma discussão explícita com a série do CCP a grande citação desses volumes nas obras de Huntington e a própria inserção de Huntington, em 1967, como participante do Comitê de Política Comparada. desenvolvimento econômico é relevante, pois altera as capacidades desses mesmos atores (HUNTINGTON, 1965; 1975).

Aprofundando a compreensão daquilo que Huntington entende por mobilização social, começa a delinear-se qual é a base da distinção entre modernização e desenvolvimento político. Não por acaso, em Huntington aparece a noção de mobilização social, proveniente de um autor da teoria do desenvolvimento político clássica, como um dos aspectos-chaves da modernização e a forma que ela afeta o desenvolvimento político. Essa aproximação indica, corretamente, a principal característica em que há uma continuidade entre os teóricos clássicos e Huntington, abrangendo também o Comitê de Política Comparada. Apesar do tema da instabilidade ainda ser um tema menor entre os clássicos da teoria do desenvolvimento político, desde aquele momento o problema da instabilidade já aparecia majoritariamente relacionado à geração de novas aspirações irrealizáveis. Em Lerner (1958) esse excesso de aspirações e desejos é produto da própria modernização da sociedade. Esta gera uma classe média, entre a antiga elite e as massas, que possui acesso aos meios de comunicação e até mesmo à graduação universitária, porém, esses processos modernizam a personalidade de antigos desprivilegiados sem que o sistema consiga, no entanto, por falta de recursos, satisfazer todos os desejos e vontades que foram despertados. Em resumo, o problema se trata, nas palavras de Lerner, de um hiato ( $g a p$ ) entre aspirações e capacidades. É essa incapacidade de satisfazer os desejos criados que gera radicais e extremistas desestabilizadores da sociedade. Em suma, o argumento é que não são aqueles que não possuem nada que desafiam o sistema, mas sim aqueles que querem mais ${ }^{19}$. Nas citações a Lerner e nos termos

19 Deutsch (1961) aponta, semelhantemente, que a mobilização social (a quebra de antigos vínculos e a geração de novos) gera novas necessidades (distinguindo-se, portanto, da terminologia de Lerner, que ao tratar como aspirações e desejos indica que compreende essas mudanças como subjetivas), que se não forem satisfeitas promovem tensões políticas. Da mesma forma, Shils (1960a; 1960b) compartilha essa correlação entre desejos não satisfeitos e instabilidade, no entanto, o autor relaciona a existência desse excesso de aspirações aos governos populistas irresponsáveis e não ao próprio processo de modernização. Também a série analisada do Comitê de Política Comparada atribui os conflitos das sociedades à promoção exagerada de expectativas, que por serem desmesuradas não puderam ser satisfeitas. 
utilizados, fica claro como Huntington deve, acima de tudo, a esse teórico da perspectiva clássica o modo como compreende a relação entre modernização e instabilidade.

Se, de um lado, o tema da relação entre modernização e instabilidade deixa transparecer aquele que é o elemento de maior aproximação entre Huntington $(1965 ; 1975)$ e a teoria clássica do desenvolvimento político, por outro, esse mesmo tema revela também a maior ruptura com a década de 1950 . Ou seja, aqui aparece uma ruptura real, conformando, portanto, uma diferença qualitativa em relação ao Comitê de Política Comparada, que apesar das inflexões temáticas não rompeu com os pressupostos do pensamento. De um lado, Huntington continua a avaliar, em uma estrutura similar, a modernização como geradora de aspirações e, conseqüentemente, frustrações. De outro, essa compreensão da modernização gera uma nova postura frente a esse processo, a qual nem os clássicos, nem mesmo o CCP, ousaram assumir. Enquanto os clássicos mantêm a questão da instabilidade como uma questão marginal, já que havia uma aposta otimista na reversão dessa situação com a continuidade do processo, e enquanto os cientistas do CCP já apresentam um pessimismo mais receoso, que não mais aposta no desenrolar "natural" do processo, mas ainda acreditam que é possível promover um sistema político capaz de lidar com os conflitos e crises, Huntington desiste de qualquer presunção de uma modernização que ao fim possa ser estável e benéfica (idem). Aliás, os efeitos benéficos de um processo de transformação global quase desaparecem do raciocínio do autor, a modernização chega a ser vista como um processo que não é sequer desejável, rompendo, portanto, definitivamente e ineditamente com a teoria clássica do desenvolvimento político. A citação abaixo indica como a manutenção de uma estrutura social de indivíduos menos conscientes e reivindicadores é vista pelo cientista político como uma alternativa possível frente a uma modernização essencialmente desestabilizadora: "Existe assim um conservadorismo dos desamparados tão profundo quanto o dos privilegiados; os primeiros constituem um fator tão importante para a perpetuação da ordem social quanto os últimos. A pobreza em si mesmo é uma barreira à instabilidade. Os que estão preocupados com o objetivo imediato da próxima refeição não estão propensos a se preocuparem com a grande transformação da sociedade" (HUNTINGTON, 1975, p. 66).
É essa rejeição da modernização como um processo positivo, assim como a desistência de buscar-se caminhos para garantir os frutos da mudança, que é entendido como um ponto de ruptura em Huntington que não havia sido realizado até $\operatorname{agora}^{20}$.

Duas conclusões parciais já são possíveis de serem elaboradas. Em primeiro lugar, percebe-se que apesar de ter ressaltado duas características do processo de modernização - o desenvolvimento econômico e a mobilização social - é a mobilização social, acima de tudo, que Huntington tem em mente quando os efeitos nefastos da modernização são apontados ${ }^{21}$. Em segundo lugar, dado que

20 Sobre esse assunto, compare a citação de Huntington do parágrafo anterior, com a citação a seguir de Deutsch que discute como lidar com as possíveis conseqüências desestabilizadoras da mobilização social: "Tais intervenções não devem ter o objetivo de retardar o desenvolvimento econômico e social. [...] Essas políticas [policies] de desacelerar a mobilização social e o desenvolvimento econômico, essencialmente, apenas reduziram as capacidades do governo, construíram o caminho para fracassos domésticos e derrotas internacionais e foram seguidas, ao longo do curso de três gerações, pelo atraso persistente e pela destruição final do Estado. Uma política [policy] mais promissora seria, ao contrário, de ação interventora a favor de um crescimento mais rápido e balanceado; uma distribuição de renda de alguma forma mais uniforme, relacionada mais proximamente às recompensas das contribuições produtivas que ao status e à herança; um investimento mais produtivo dos recursos disponíveis; e um crescimento sustentável das capacidades administrativas e políticas do governo e do estrato cada vez mais amplo da população" (DEUTSCH, 1961, p. 505).

21 Nas palavras de Huntington: “A mobilização social é muito mais desestabilizadora que o desenvolvimento econômico. O hiato entre essas duas formas fornece uma medida para o impacto da modernização na estabilidade política. A urbanização, a alfabetização, a educação, os meios de massa e outros fatores expõem o homem tradicional a novas formas de vida, a novos padrões de prazeres, a novas possibilidades de satisfação. Essas experiências rompem as barreiras cognitivas e atitudinais da cultura tradicional e promovem novos padrões de aspirações e anseios. Mas a capacidade de uma sociedade em transição de satisfazer essas novas aspirações aumenta num ritmo muito mais lento que as aspirações em si. Conseqüentemente, desenvolve-se um hiato entre aspirações e expectativas, a formação do anseio e a sua satisfação, entre a função das aspirações e a função do nível de vida real. Esse hiato gera a frustração social e a insatisfação. Na prática, a extensão do hiato proporciona uma medida razoável da instabilidade política" (HUNTINGTON, 1975, p. 66). 
é essa modernização quase sinônimo de mobilização social que apresenta, em sua perspectiva, os efeitos mais devastadores, é possível entender por que é a modernização em geral, mais do que o desenvolvimento econômico especificamente, o principal objeto de confronto do cientista político.

A reconstrução do pensamento até aqui, assim como as passagens selecionadas, já permitem compreender o que Huntington entende por modernização. Resta ainda esclarecer o que seria então desenvolvimento político. O desenvolvimento político, fenômeno independente da modernização, é definido como o processo de institucionalização de organizações políticas e procedimentos. O significado dessa virada para as instituições precisa ser mais bem qualificado.

Diversas análises já criticaram Huntington por ter anunciado uma nova perspectiva de abordagem institucional, quando a análise das instituições políticas, de fato, está ausente de seu pensamento (KAZEMI, 1969; REMMER, 1997; DOMÍNGUEZ, 2001) Exceto os partidos, todas as outras instituições - burocracia, Congresso, sistema judiciário, agências e departamentos - não são consideradas. Remmer (1997) afirma que essas ausências demonstram como Huntington não representou o primeiro passo para o estudo das instituições políticas, mas sim a culminação de uma linha de pesquisa - a desenvolvimentista - que não conseguiu cumprir o papel de entender o sistema político nas sociedades em mudança.

Nessa discussão a respeito do avanço e do legado do pensamento de Huntington parece haver uma identificação apressada ${ }^{22}$ entre o institucionalismo de Huntington e outras vertentes que ficaram mais conhecidas na história da Ciência Política (refiro-me ao institucionalismo anterior à II Guerra Mundial e ao neo-institucionalismo emergente a partir da década de 1970). Como aparece explícito no artigo, a análise institucional

\footnotetext{
22 Apressada, porém compreensível, já que foi justamente no período dessas obras de Huntington que o paradigma comportamentalista (behaviorist) começou a entrar em declínio na Ciência Política como um todo e o neoinstitucionalismo começou a emergir como alternativa. Sobre o assunto, ver Peres (2008). No entanto, essas transformações parecem ter atingido o estudo dos países em mudança mais tardiamente (cf. REMMER, 1997).
}

de Huntington não se aproxima da compreensão do que acontece com a black box ${ }^{23}$ do Estado, ao contrário "institucionalização" é entendida como o "processo por meio do qual organizações e procedimentos adquirem valor e estabilidade" (HUNTINGTON, 1965, p. 394; 1975, p. 24) A existência de procedimentos reconhecíveis e estáveis que regulam a participação política, assim como a resolução de conflitos, é que garante a estabilidade das sociedade como um todo. A citação a seguir indica esse ponto: "Tanto a sociedade de massa quanto a sociedade participante possuem elevados níveis de participação política. Diferem, porém, na institucionalização das organizações e dos procedimentos políticos. Na sociedade de massa, a participação política é nãoestruturada, inconstante, anômica e variada. Cada força social procura atingir seus objetivos por meio dos recursos e das táticas em que é mais forte. A apatia e a revolta sucedem uma a outra, filhas gêmeas da ausência de símbolos e instituições políticas com autoridade. A forma característica de participação política é o movimento de massa, combinando ações violentas e não violentas, legais e ilegais, coercitivas e persuasivas. A sociedade de massa carece de estruturas organizadas que possam relacionar os desejos e atividades políticas das massas com os objetivos e decisões de seus líderes" (HUNTINGTON, 1975, p. 101).

Considerando o que Huntington entende por modernização e por desenvolvimento político, fica claro como é possível sintetizar em apenas uma frase o fulcro da distinção entre ambos os conceitos: se a modernização seria responsável pelos efeitos desestabilizadores, o desenvolvimento político é aquele que gera a estabilidade.

\section{CONCLUSÕES}

Em síntese, a série "Estudos do Desenvolvimento Político", distanciando-se da perspectiva clássica, apresenta uma apreensão crescente a respeito do curso da África, da Ásia e da América Latina. A "revolução das frustrações crescentes" e os problemas que essa revolução gera colocam ao analista a necessidade de preocupar-se com o equilíbrio, a prudência e a responsabilidade. Essa

23 Segundo a vertente neo-institucionalista, as instituições políticas seriam a black box da política, isto é, é necessário introduzi-las na análise para entender-se como interesses societais são traduzidos em policies. 
responsabilidade exige uma nova atitude frente ao desenvolvimento rápido, uma vez que o desenvolvimento econômico afeta a estabilidade social. Essas novas preocupações com as expectativas e frustrações, com o equilíbrio e a estabilidade e com os efeitos das rápidas transformações econômicas no sistema político acabam formando uma teoria do desenvolvimento político como processo autônomo do desenvolvimento econômico. Mais do que isso, uma teoria que responde às novas apreensões em relação ao futuro dos países, assumindo como fim teórico entender a construção da estabilidade, em vez do objetivo até então existente de promover a transformação global da sociedade.

No caso de Huntington, três pontos são fundamentais para a compreensão da representação definitivamente securitizada que aparece em suas obras. Em primeiro lugar, a diferenciação entre modernização e desenvolvimento político é, em parte, justificada pela distância entre o que o cientista político entende por desenvolvimento político e a "realidade" das sociedades em mudança. Em segundo lugar, Huntington rompe, ineditamente, com a teoria clássica ao formatar uma nova visão quase exclusivamente negativa do processo de modernização, chegando a vê-lo como indesejável. Por último, deve-se atentar para a forma com que Huntington correlaciona desenvolvimento político e estabilidade. Desenvolvimento político é entendido como institucionalização de organizações políticas e procedimentos, sendo "institucionalização o processo por meio do qual organizações e procedimentos adquirem valor e estabilidade" (HUNTINGTON, 1965, p. 394) Todos esses pontos somados explicam o radicalismo da nova representação securitizada: a instabilidade não é apenas um elemento constante, mas desponta quase sozinha como base para a representação dos países pobres. Observe a citação a seguir: "Com poucas notáveis exceções, a evolução política desses países depois da II Guerra Mundial caracterizou-se por crescentes conflitos étnicos e de classe, intermitentes motins e violência de massa, freqüentes golpes de estado militares, domínio de instáveis líderes personalistas que tomaram quase sempre medidas econômicas e sociais desastrosas, corrupção generalizada e clamorosa entre ministros e funcionários públicos, violação arbitrária dos direitos e liberdades dos cidadãos, declínio dos padrões de eficiência e desempenho da burocracia, profunda alienação de grupos políticos urbanos, perda de autoridade de legislativos e tribunais, fragmentação e às vezes desintegração completa de partidos políticos de ampla base" (HUNTINGTON, 1975, p. 15).

Segundo Fukuyama (2006), o ano em que o livro de Huntington foi publicado (1968) era também o ano em que a política americana, até então guiada por estratégias de desenvolvimento como alternativas para os apelos do comunismo, estava dando sinais de fracasso. Como essas transformações internas na teoria geraram um novo entendimento a respeito dos problemas dos países pobres e, com isso, a formulação de uma nova ação política de enfrentamento a esses problemas? A partir do momento em que não havia mais uma compreensão dos dilemas como resultado da ausência de desenvolvimento, também as estratégias de modernização deixaram de ser consideradas eficientes. Se o problema era de excesso de aspirações e frustrações que geravam desordem, um novo objetivo deveria ser buscado no lugar de um desenvolvimento desestabilizador. Fukuyama também argumenta, na citação a seguir, que a transformação da teoria do desenvolvimento político cumpriu um papel na formatação de novas estratégias políticas: "Huntington traçou, então, o fundamento para uma estratégia de desenvolvimento que passou a ser chamada de 'transição autoritária', a qual uma ditadura modernizante fornecia ordem política, o primado da lei e condições para o sucesso do desenvolvimento social e econômico" (idem, p. XIII).

O arsenal teórico de Koselleck (2006) contribui para pensarmos a relação entre transformações teórico-conceituais e a história. Segundo ele, a linguagem não deve ser pensada apenas em seu papel de descrição do mundo, mas também como meio a partir do qual se elabora e comunica novos mundos possíveis. A comunicação dessas novas possibilidades acontece no momento em que a linguagem abarca determinado fenômeno ou reconstrói uma ou outra visão disseminada, conferindo, com isso, sentido à ação do ator. Segundo Koselleck, esse papel da linguagem em elaborar novas formas, de modo a dar sentido aos acontecimentos, indica como a história só pode ser compreendida na medida em que haja uma linguagem que a fundamente e a abarque. Isso quer dizer que a nova linguagem que estava sendo construída fundamentava as preocupações com os conflitos, ressignificava os novos acontecimentos de modo a dar sentido à nova reorganização de estratégias e legitimava o interesse na capacidade de os sistemas políticos responderem aos conflitos e às de- 
mandas para manterem a ordem, em vez de promoverem a transformação. Portanto, se em certa medida a nova linguagem emergiu por causa de algumas características presentes naquele contex$\mathrm{to}^{24}$, em outro sentido, o sucesso que tiveram aquelas novas formulações e novas temáticas em abarcar e dar sentido àquela situação acabou tendo o efeito de reforçar o statu quo (JASMIN, 2007).

E tal reforço pode ser percebido duplamente em nosso tema. Em primeiro lugar, ele atua de modo a dar sentido a uma nova preocupação de política externa mais voltada para as capacidades de estabilização do que para as possibilidades modernizadoras. Em segundo lugar, o reforço do statu quo é amplificado por ter dado um novo sentido aos acontecimentos das décadas de 1960 e 1970. Com essa nova linguagem, os acontecimen- tos nos países em transição puderam ser entendidos como demonstrações de um desenvolvimento dramático, que promovia um excesso de demandas e, com isso, excesso de crises, ocorrendo ao mesmo tempo ou em uma seqüência que não permitia construção de capacidades. Enfim, um desenvolvimento cíclico, que precisava ser induzido, mas que não havia lideranças nem instituições capazes de controlá-lo ou regulá-lo.

Nesse sentido, como reforçador do statu quo e estimulador de uma visão crítica de todos os acontecimentos que afetavam a ordem, é possível questionar em que medida a construção de uma nova linguagem nos anos 1960 não possui uma parcela de responsabilidade pelo desencontro entre os países pobres e os Estados Unidos na década de 1970, período que já foi chamado de "década das crises perpétuas" 25 .

Natália Nóbrega de Mello (nataliamello@yahoo.com) é Mestre em Ciência Política pela Universidade de São Paulo (USP) e Professora de Relações Internacionais das Faculdades Metropolitanas Unidas (FMU).

\section{REFERÊNCIAS BIBLIOGRÁFICAS}

ALMOND, G. \& COLEMAN, J. 1969. A politica das áreas em desenvolvimento. Rio de Janeiro: F. Bastos.

BINDER, L.; COLEMAN, J.; LAPALOMPARA, J.; PYE, L.; VERBA, S. \& WEINER, M. 1971. Crises and Sequences in Political Development. Princeton: Princeton University.

WALLERSTEIN, I. 1998. The Unintended Consequences of Cold War Area Studies. In: CHOMSKY, N.; MONTGOMERY, D.; LEWONTIN, R.; ZINN, H.; OHMANN, R.; NADER, L.; SIEVER, R.; WALLERSTEIN, I. \& KATZNELSON, I. The Cold War \& the University: Toward and Intellectual History of the Postwar Years. New York: The New Press.

COLEMAN, J. (ed.). 1965. Education and Political Development. Princeton: Princeton University.

DEUTSCH, K. 1961. Social Mobilization and Political Development. The American Political Science Review, Los Angeles, v. 55, n. 3, p. 493-514, Sep.

24 Indico novamente Mello (2009) para uma análise de como o contexto, por sua vez, influenciou as transformações teóricas.
DOMíNGUEZ, J. 2001. Samuel Huntington and the Latin American State. In: CENTENO, M. A. \& LÓPEZ-ALVES, F. (eds.). The Other Mirror: Grand Theory Through the Lens of Latin America. Princeton: Princeton University.

FUKUYAMA, F. 2006. Foreword by Francis Fukuyama. In: HUNTINGTON, S. Political Order in Changing Societies. New Haven: Yale University.

GENDZIER, I. 1985. Managing Political Change: Social Scientist and the Third World. Boulder: Westview.

1998. Play it Again Sam: the Practice and Apology of Development. New Political Science, Oxford, v. 20, n. 2, p. 159-183, June.

GILMAN, N. 2003. Mandarins of the Future: Modernization Theory in Cold War America. Baltimore: Johns Hopkins University.

GREW, R. 1978. Crises of Political Development in Europe and the United States. Princeton: Princeton University.

25 Modo como a década de 1970 é chamada por Kolko (1988). 
HUNTINGTON, S. 1965. Political Development and Political Decay. World Politics, Baltimore, v. 17, n. 3 , p. $386-430$, Apr.

1975. A ordem política nas sociedades em mudança. São Paulo: USP.

JASMIN, M. 2007. Lenguajes politicos en el mundo de la acción: historia conceptual y teoría política. Prismas, Buenos Aires, n. 11, p 171176.

KAZEMI, F. 1969. Review. Iranian Studies, New York, v. 2, n. 4, p. 175-179, Autumn.

KENSKI, H. 1975. Teaching Latin American Politics at American Universities: a Survey. Latin American Research Review, Baltimore, v. 10, n. 1, p. 89-104, Spring.

KOLKO, G. 1988. Confronting the Third World: United States Foreign Policy 1945-1980. New York: Pantheon.

KOSELLECK, R. 2006. Futuro Passado: contribuição à semântica dos tempos históricos. Rio de Janeiro: Contraponto.

LAPALOMBARA, J. (org.). 1973. Burocracia y desarrollo político. Buenos Aires: Paidos.

LAPALOMBARA, J. \& WEINER, M. (eds.). 1972. Political Parties and Political Development. Princeton: Princeton University.

LATHAM, M. 2000. Modernization as Ideology: American Social Science and "Nation-Building" in the Kennedy Era. Chapel Hill: The University of North Carolina.

LERNER, D. 1958. The Passing of Traditional Society: Modernizing the Middle East. London: Free.

LEVY JR., M. 1952. The Structure of Society. Princeton: Princeton University.

MELLO, N. 2009. Do desenvolvimento global ao paradigma da ordem e da estabilidade: representações dos países pobres na teoria do desenvolvimento político norte-americana. São Paulo. Dissertação (Mestrado em Ciência Política). Universidade de São Paulo. Disponível em: http://www.teses.usp.br/teses/disponiveis/ 8/8131/tde-09022010-123329/publico/ NATALIA_NOBREGA_MELLO.pdf. Acesso em: 29.abr.2011.
MONTGOMERY, J. 1969. Review: The Quest for Political Development. Journal of Comparative Politics, New York, v. 1, n. 2, p. 285-295, Jan.

O'BRIEN, D. 1972. Modernization, Order, and the Erosion of a Democratic Ideal: American Political Science 1960-1970. Journal of Development Studies, New York, v. 8, n. 4, p. 351-378, July.

PACKENHAM, R. 1973. Liberal America and the Third World: Political Development Ideas in Foreign Aid and Social Science. Princeton: Princeton University.

PERES, P. 2008. Comportamento ou instituições? A evolução histórica do neo-institucionalismo na Ciência Política. Revista Brasileira de Ciências Sociais, São Paulo, v. 23, n. 68, p. 5371, out. Disponível em: http://www.scielo.br/ pdf/rbcsoc/v23n68/v23n68a05.pdf . Acesso em: 29.abr.2011.

PYE, L. (org.). 1967. Comunicações e desenvolvimento político. Rio de Janeiro: J. Zahar.

PYE, L. \& VERBA, S. (eds.). 1969. Political Culture and Political Development. Princeton: Princeton University.

REMMER, K. 1997. Theoretical Decay and Theoretical Development: the Resurgence of Institutional Analysis. World Politics, Baltimore, v. 50, n. 1 , p. $34-61$, Oct.

ROTBERG, R. 2003. State Failure and State Weakness in a Time of Terror. Washington (DC): Brookings.

SHILS, E. 1960a. Political Development in the New States. Comparative Studies in Society and History, Cambridge (UK), v. 2, n. 3, p. 265-292, Apr.

1960b. Political Development in the New States II. Comparative Studies in Society and History, Cambridge (UK), v. 2, n. 4, p. 379411, July.

TILLY, C. 1975. The Formation of National States in Western Europe. Princeton: Princeton University.

WARD, R. \& RUSTOW, D. (eds.). 1968. Political modernization in Japan and Turkey. Princeton: Princeton University. 